\title{
Characterization of Phosphate Solubilizing Faba Bean (Vicia faba L.) Nodulating Rhizobia Isolated from Acidic Soils of Wollega, Ethiopia
}

\author{
Girmaye Kenasa ${ }^{1,2^{\star}}$, Mulissa $\mathrm{Jida}^{1}$ and Fassil Assefa ${ }^{2}$ \\ ${ }^{1}$ Department of Biology, College of Natural and Computational Sciences, Wollega University, \\ Post Box No: 395, Nekemte, Ethiopia \\ ${ }^{2}$ Addis Ababa University, Department of Microbial, Cellular and Molecular Biology, \\ Post Box No: 1176, Addis Ababa, Ethiopia
}

\begin{abstract}
Some species of rhizobial bacteria nodulating faba bean are characterized by phosphate solubilization. In order to study their in vitro and symbiotic characteristics, twelve rhizobial isolates nodulating faba bean were collected from acidic soil of Wollega, Ethiopia. Solubilization index of the isolates ranges from 1.25 to 2.10. Mean Generation Time of the isolates were less than 2.34; and growth of isolates on Yeast Extract Mannitol agar with bromothymoleblue media were accompanied by change of color from blue to yellow. AUAVR51 and AUAVR-52 were the highest in TCP-Solubilizion Index. The two isolates were also recognized as stress tolerant when tested in vitro for extreme temperature, osmotic, acidic $\mathrm{pH}$, intrinsic antibiotics, and acidic-aluminum as compared to the other isolates. However, there was no unique metabolic diversity and specialization of AUAVR-51 and AUAVR-52 isolates with respect to carbon and nitrogen source utilization. On the other hand, isolates AUAVR-51 and AUAVR-52 were characterized by effective and highly effective symbiosis on sterile potted sand growth, respectively. In general, phosphate solubilizing rhizobia nodulating faba bean from acidic soil are fast grower; and their solubilization potential varies. However, the contribution of these isolates as double fertilizer should be tested in the real acidic soil characterized by immobilized phosphorous.
\end{abstract}

Article Information

Copyright@2014 STAR Journal. All Rights Reserved. Article History:

Received : 08-06-2014

Revised : 10-09-2014

Accepted : 19-09-2014

Keywords:

Faba bean

Rhizobial isolates

Phosphate solubilization

Symbiotic effectiveness

${ }^{*}$ Corresponding Author: Girmaye Kenasa

E-mail:

girmayek@gmail.com

\section{INTRODUCTION}

Faba bean (Vicia faba L.) is a leguminous crop grown in Ethiopia mainly in "Weyna Dega" climatic condition that ranges in altitude from 1800 to 2400 m.a.s.l. Grain seeds of the crop is known by high protein content. This is due to the effective symbiotic nitrogen fixing bacterial species generally called Rhizobium leguminosarum bv. Viciae that form association with roots of the crop (Zahran, 1999). Faba bean in association with the strain can fix up to 325 $\mathrm{kg}$ of $\mathrm{N}_{2} \mathrm{~h}^{-1} \mathrm{y}^{-1}$ (Somasegaran and Hoben, 1994). As a result, the crop is found to be very efficient $\mathrm{N}_{2}$ fixer and can meet its entire nitrogen requirement through BNF (Abere Mnalku et al., 2009; Zerihun Belay and Fassil Assefa, 2011 and Anteneh Argaw, 2012). This also improves soil nitrogen content that is in turn increases the yield of subsequent crops in cropping system.

Effective symbiotic association between rhizobial strain and host depends on different soil condition such as salinity, drought, acidity, and soil temperature (Zaharan, 1999). Although some parts of Wollega are major faba bean producing area, the symbiosis could be harnessed by a very low $\mathrm{pH}$, a very high exchangeable acidity, low calcium, and potassium properties of the soil (Abdenna Deressa et al., 2013). The low pH of the soil results in immobilization of phosphorous by aluminum, and iron ions. As a result, phosphorous availability as plant nutrient is limited, which in turn strap up energy acquisition for nitrogen fixation. However, there are legume nodulating bacteria such as Rhizobium, Bradyrhizobium, and Mesorhizobium strains possessing properties of solubilizing immobilized organic and inorganic phosphate sources (Halder et al., 1990 and Peix et al., 2001). Thus, besides the fixation of atmospheric nitrogen to its utilizable form, these bacteria also contribute to the growth of plants through solubilizing inorganic phosphates of low solubility. Specifically, the better potential of Rhizobium leguminosarum bv. viciae in solubilizing inorganic phosphate sources were reported by Alikhani et al. (2006).

On the other hand, there is variation in stress tolerance among different strains of Rhizobium leguminosarum. These variability is an important tools to measure the survival advantage of one strain over the other in the sever soil environment (Rice et al., 1977). Strains resistant to different soil stresses have potential to improve the production of legumes grown on the area; and extend the ranges of soils upon which legumes adapted to grow (Munns, 1978). Metabolic versatility and specialization among rhizobial strains enables some strain 
Girmaye Kenasa et al.,

to persist in adverse environments and compete successfully with other bacteria (Mazur et al., 2013). Therefore, the ability of legume-nodulating rhizobia to solubilise different inorganic phosphates sources, the potential to tolerate wide range of stress, and versatility in metabolism should be considered when selecting strains as biofertilizer. These properties are important for competitiveness and survival of inoculants with indigenous microflora. Thus, the main objective of this study was to isolate and characterize phosphate
Sci. Technol. Arts Res. J., July-Sep 2014, 3(3): 11-17

solubilizing faba bean rhizobial isolates from acidic soil of Wollega.

\section{MATERIALS AND METHODS}

\section{Rhizobial Bacteria Isolation}

Faba bean root nodules were collected from farmers' field during its flowering stage in vials containing silica gel plugged with cotton. Totally 44 root nodule samples were taken from faba bean producing areas of Wollega (figure 1).

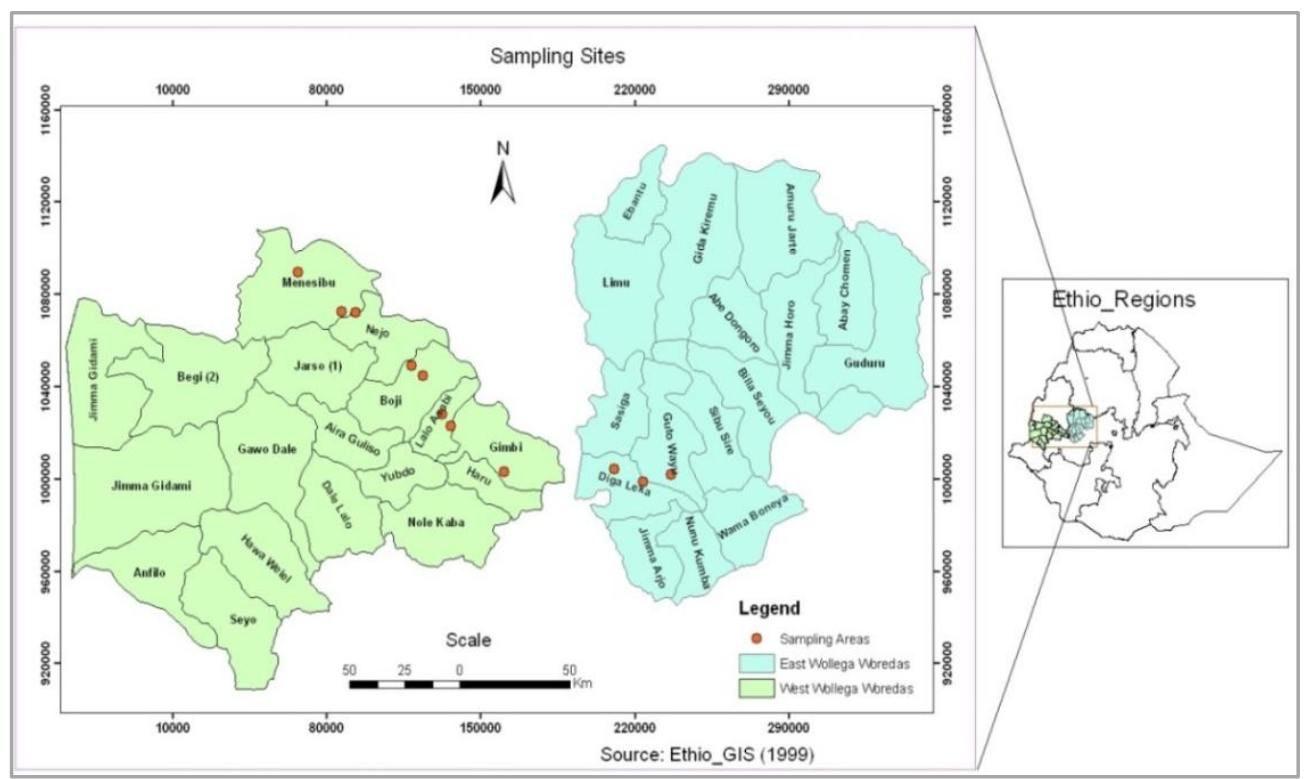

Figure 1: Sampling area.

Isolation and preservation of root nodule bacteria were carried out as described in Vincent (1970). Purity of the isolates was checked by Congo Red absorption on Yeast Extract Mannitol Agar (YEMA) (in $\mathrm{g} / \mathrm{l}$ of distilled water; mannitol, 10; yeast extract, $1 ; \mathrm{K}_{2} \mathrm{HPO}_{4}, 0.5 ; \mathrm{MgSO}_{4} .7 \mathrm{H}_{2} \mathrm{O}$, $0.2 ; \mathrm{NaCl}, 0.1$; agar, 15 and congored, 0.025), and growth on peptone-glucose agar (in $\mathrm{g} / \mathrm{l}$ distilled water, glucose, 5; peptone, 10; agar, 15 and $\mathrm{pH}, 6.7$ ).

Table 1: Sampling area of the isolates.

\begin{tabular}{|c|c|c|c|c|}
\hline \multirow{2}{*}{ Isolates } & \multicolumn{3}{|c|}{ Sampling Sites } & \multirow{2}{*}{$\begin{array}{l}\text { Soil } \\
\text { pH }\end{array}$} \\
\hline & Zone & Woredas & Kebeles & \\
\hline AUAVR-12 & EW & Gudeya Bila & Jawaja & 4.8 \\
\hline AUAVR-13 & $"$ & Bila Sayo & Anno & 4.8 \\
\hline AUAVR-14 & " & $"$ & Anno & 4.6 \\
\hline AUAVR-29 & $"$ & $"$ & Tilili & 4.9 \\
\hline AUAVR-30 & $"$ & Sibu Sire & Chafe & 4.9 \\
\hline AUAVR-34 & $"$ & " & Chafe & 4.8 \\
\hline AUAVR-39 & " & $"$ & Moto & 5.0 \\
\hline AUAVR-47 & $"$ & Gute & Warababo & 5.2 \\
\hline AUAVR-49 & WW & Gimbi & Enango & 6.3 \\
\hline AUAVR-51 & $"$ & $"$ & Enango & 5.6 \\
\hline AUAVR-52 & $"$ & $"$ & Lalisa Eyasus & 5.3 \\
\hline AUAVR-53 & $"$ & Lalo Asabi & Jiru & 5.3 \\
\hline
\end{tabular}

\section{Growth media, Incubation and Experimentation}

In the entire of this experiment the growth media was YEMA, and incubation temperature was $28 \pm 2^{\circ} \mathrm{C}$ for 5 days. All growth media were sterilized at $121^{\circ} \mathrm{C}$ for 15 minutes, and 72 hrs old liquid growth cultures with approximate viable cell number of $10^{9} \mathrm{ml}^{-1}$ was used for inoculation unless stated otherwise.

\section{Soil pH Measurements}

The collected soil samples from the sampling sites were dried and sieved to less than $2 \mathrm{~mm}$; then $10 \mathrm{~g}$ of the soils were dissolved in $50 \mathrm{ml}$ of deionized water (1:5 ratios). The container was shaked for about $3 \mathrm{~min}$ and the residue was allowed to settle for 2 min. Finally, $\mathrm{pH}$ readings were taken by $\mathrm{pH}$ meter.

\section{Phosphate Solubilization Test}

Tri-calcium phosphate solubilization (TCP) potential of the isolates was determined using Basal Sperber agar media (Sperber, 1958). Component of Basal Sperber agar media was (in $\mathrm{g} / \mathrm{l}$ of distilled water: glucose, 10.0; yeast extract, 0.5; $\mathrm{CaCl}_{2}, 0.1 ; \mathrm{MgSO}_{4} .7 \mathrm{H}_{2} \mathrm{O}, 0.25$; and agar, 15.0; $\mathrm{Ca}_{3}(\mathrm{PO} 4)_{2}, 2.5$; and $\mathrm{pH}$ adjusted at 7.2 before autoclaving). Solubilization Index (SI) was estimated according to Edi-premono et al. (1996).

\section{Authentication}

Authentication of the rhizobial isolates was conducted in Growth Pouch using faba bean called "Moti" obtained from Holeta Agricultural Research center. The procedure for seed surface sterilization was the same as the one described for nodule surface sterilized. The seedlings were inoculated with the rhizobial isolates grown on YEM broth $(1 \mathrm{ml} /$ seedling) after appearance of secondary leaf. Growth Pouches containing uninoculated seedling were included as controls. All Growth Pouches were fertilized with quarter strength of Broughton and Dilworth $\mathrm{N}$-free medium twice per week (Somasegaran and Hoben, 1994). Distilled sterile water was added whenever required. After 30 days of planting, the crops were checked for nodulation both in the inoculated and uninoculated Growth Pouches. The authenticated isolates 
Girmaye Kenasa et al.,

were designated as AUAVR (Addis Ababa University Acidic soil Vicia faba Rhizobium) with different numbers to differentiate one isolate from the other.

\section{Morphological Growth \& Biochemical Characteristics of the Isolates}

The isolates were characterized by colony morphology and acid/alkaline production on YEMA plus $25 \mu \mathrm{gml}^{-}$ ${ }^{1}$ Bromothymoleblue (BTB) media (Ahmed et al., 1984). Growth rate of the rhizobial isolates was estimated by measuring optical density (OD) using spectrometer from YEM-broth. OD readings were taken at $540 \mathrm{~nm}$ beginning from time of inoculation (Ohr) up to the $96^{\text {th }}$ hour at every $6 \mathrm{hrs}$ interval. Finally, mean generation time (g) was calculated from the logarithmic phase as indicated on White (1995).

\section{Stress Tolerance Test}

Tolerance of the isolates to extreme temperature, $\mathrm{pH}$, and salt was checked according to Maatallah et al. (2002). Intrinsic antibiotics resistance (IAR) of isolates to Kanamycin sulfate, Streptomycin sulfate, Chloramphenicol, Ampicillin, Neomycin sulfate and Erythromycin with concentration of $(\mu \mathrm{g} / \mathrm{ml}) 2.5,5$, and 10 was tested. Metals toxicity tolerance level of the isolates was checked at concentration of $(\mu \mathrm{M}) 50,100$, and 150 on Keyser solid media (Lupwayi and Haque, 1994). The metals were Aluminum ( $\mathrm{Al}$ ) in the form AlK $\left(\mathrm{SO}_{4}\right)_{3} .12 \mathrm{H}_{2} \mathrm{O}$ and Manganese $(\mathrm{Mn})$ in the form of $\mathrm{MnCl}_{4} \cdot 4 \mathrm{H}_{2} 0$. Stock solutions of the antibiotics and metals was prepared; and sterilized by membrane filtration(pore size of $0.22 \mu \mathrm{m}$ ). The required concentration was added to autoclaved media that was cooled to $50^{\circ} \mathrm{C}$ on water bath.

\section{Substrate Utilization Test}

Growth of isolates on different Carbon and nitrogen sources was checked. The carbon sources were added at a final concentration of $1 \mathrm{~g} / \mathrm{l}$ to a basal medium containing (per liter of distilled water: $1 \mathrm{~g}$ of $\mathrm{K}_{2} \mathrm{HPO}_{4}, 1 \mathrm{~g}$ of $\mathrm{KH}_{2} \mathrm{PO}_{4}$, $0.01 \mathrm{~g}$ of $\mathrm{FeCl}_{3} .6 \mathrm{H}_{2} \mathrm{O}, 0.2 \mathrm{~g}$ of $\mathrm{MgSO}_{4} .7 \mathrm{H}_{2} \mathrm{O}, 0.1 \mathrm{~g}$ of $\mathrm{CaCl}_{2}, 1 \mathrm{~g}$ of $\left(\mathrm{NH}_{4}\right)_{2} \mathrm{SO}_{4}$, and $15 \mathrm{~g}$ of agar. The amino acids were added at a concentration of $0.5 \mathrm{~g} / \mathrm{l}$ to a similar media from which ammonium sulfate was omitted and mannitol was added at a concentration of $1 \mathrm{~g} /$ liter (Amarger et al. 1997). The carbohydrates sources were D-arabinose, D-galactose, D-mannose, Maltose, Dextrin, D-glucose, D-fructose, Sucrose and Mannitol. The nitrogen sources were L-aspargine, L-glutamate, Ltryptophan, L-tyrosine, L-alanine, L-arginine, Methionine, and Lysine. All of the substrates were filter sterilized using $0.22 \mu \mathrm{m}$ membrane and added to autoclaved basal media that was cooled to $50^{\circ} \mathrm{C}$ on water bath

\section{Symbiotic Efficiency Test on Sterile Sand}

Plastic pots (4kg capacity) were filled with acid washed and autoclave sterilized sand. Seed surface sterilization and seedling inoculation were done as described before for authentication. Both positive and negative controls were included as treatments. The positive control pots received $120 \mathrm{ml}$ of $0.05 \%(\mathrm{w} / \mathrm{v})$ of $\mathrm{KNO}_{3}$ during inoculation and after 21 days as nitrogen source, whereas the negative control pots were devoid of both nitrogen sources and rhizobial isolates. After 45 days of planting, plants were harvested and the symbiotic effectiveness parameters such as nodule number(NN), nodule dry weight(NDW) (g/plant), and shoot dry weight(SDW) (g/plant) were recorded, and relative symbiotic
Sci. Technol. Arts Res. J., July-Sep 2014, 3(3): 11-17

effectiveness(\%SE) was calculated according to (Beck et al., 1993). Using the formula set by Beck et al. (1993) percentage symbiotic effectiveness of the isolates was calculated. Shoot dry weight and nodule dry weight were measured after oven drying at $70^{\circ} \mathrm{C}$ for $48 \mathrm{hrs}$.

\section{Data Analysis}

Comparison among treatments was analyzed by oneway ANOVA (Turkey's and Tamhane's T2 tests) using the statistical program SPSS-15 software.

\section{RESULTS AND DISCUSSION}

Faba bean root nodule inhabiting bacteria were isolated and tested for TCP-solubilization on agar media. Totally, twelve isolates were found to be TCP-solubilizer. Soil pH of sampling sites ranges from 4.8 to 6.3 (table 1). The isolates were gram negative and rod-shaped bacteria; and re-nodulated the host legume with pink/red color nodule. This proves that the bacterial isolates were rhizobia that form symbiotic association with faba bean. It is already identified that Vicia faba nodulating rhizobia are Rhizobium leguminosarum bv. Viciae (Somasegaran and Hoben, 1994). The rhizobial isolates changed the blue color of YEMA-BTB to yellow which is the characteristic of fast growing rhizobia due to acid production (Jordan, 1984). The change in color of YEMABTB from blue to Yellow by faba bean rhizobial isolates was also reported by Zerihun Belay and Fassil Assefa (2013).

Colony diameters of the isolates were in the range of 3 to $5 \mathrm{~mm}$ (table 2). The largest colony diameter was displayed by AUAVR-34. All isolates displayed large and mucoid colonies texture. Mean generation time of the rhizobial isolates was in the ranges of 1.43 to $2.34 \mathrm{hrs}$ (table 2). Isolate AUAVR-49 was the lowest in mean generation time. Production of organic acid, large colony size, and short mean generation time is the characteristics of fast growing rhizobial isolates (Sadowsky et al., 1983). Characteristic of the isolates such as colony diameter, mean generation time, colony texture, and growth properties on YEMA+BTB proved that all the isolates were fast-grower. The same was reported by Zerihun Belay and Fassil Assefa (2011) for Vicia faba rhizobia isolated from North Gonder, Ethiopa. Nevertheless, there was no correlation between soil $\mathrm{pH}$ of the sampling area, colony diameter, and mean generation time in the current research (table 2).

The Phosphate Solubilization Index (PSI) of the rhizobial isolates was in the range of 1.25 to 2.10 (table 2). AUAVR-51 and AUAVR-52 were the highest solubilizers. According to Alikhani et al. (2006), among the different rhizobial species collected from different kinds of host, a group of Rhizobium leguminosarum bv. viciae mobilized phosphate from TCP significantly than other species. The release of soluble phosphate significantly correlated with a drop in the $\mathrm{pH}$ of the culture filtrates, indicating the importance of acid production in the mobilization process (Song et al., 2008). Unlike the fast grower- rhizobium species, the abundance of TCPmobilizers among bradyrhizobium species are less common (Alikhani et al., 2006). This indicates that TCPmobilization is linked with acid productions, which is a typical characteristic of fast-grower rhizobia. 
Table 2: cultural and symbiotic properties of TCP-solubilizer Vicia faba rhizobia

\begin{tabular}{|c|c|c|c|c|c|c|c|c|}
\hline Strains & SI & CD & MGT(hr) & NN plant $^{-1}$ & NDW plant ${ }^{-1}$ & SDW plant ${ }^{-1}$ & SE\% & \\
\hline AUAVR-12 & 1.88 & 4.5 & 2.34 & $101 \pm 11.27^{\mathrm{a}-\mathrm{f}}$ & $0.106 \pm 0.003^{a b}$ & $1.523 \pm 0.473^{b-k}$ & 68.94 & Effective \\
\hline AUAVR-13 & 1.25 & 4.5 & 2.22 & $98 \pm 13.12^{\mathrm{a}-\mathrm{g}}$ & $0.100 \pm 0.004^{\mathrm{ab}}$ & $1.651 \pm 0.479^{a-i}$ & 75.40 & Effective \\
\hline AUAVR-14 & 1.90 & 2.5 & 2.03 & $104 \pm 14.73^{\mathrm{a}-\mathrm{e}}$ & $0.091 \pm 0.003^{b}$ & $1.327 \pm 0.025^{g-k}$ & 60.27 & Effective \\
\hline AUAVR-29 & 1.26 & 3.5 & 1.46 & $110 \pm 8.72^{a-c}$ & $0.081 \pm 0.002^{b}$ & $1.790 \pm 0.105^{\mathrm{a}-\mathrm{e}}$ & 81.74 & Highly Effective \\
\hline AUAVR-30 & 1.27 & 4.5 & 1.99 & $90 \pm 13.65^{b-h}$ & $0.055 \pm 0.004^{b}$ & $1.760 \pm 0.131^{a-f}$ & 78.54 & Effective \\
\hline AUAVR-34 & 1.50 & 5.0 & 1.53 & $107 \pm 10.58^{a-d}$ & $0.074 \pm 0.006^{b}$ & $1.426 \pm 0.042^{\mathrm{d}-\mathrm{k}}$ & 64.84 & Effective \\
\hline AUAVR-39 & 1.50 & 4.0 & 1.5 & $98 \pm 12.58^{\mathrm{a}-\mathrm{f}}$ & $0.063 \pm 0.005^{b}$ & $1.407 \pm 0.084^{\mathrm{e}-\mathrm{k}}$ & 64.38 & Effective \\
\hline AUAVR-47 & 1.31 & 4.0 & 1.81 & $97 \pm 7.81^{\mathrm{a}-\mathrm{g}}$ & $0.108 \pm 0.012^{\mathrm{ab}}$ & $1.740 \pm 0.082^{\mathrm{a}-\mathrm{g}}$ & 79.45 & Effective \\
\hline AUAVR-49 & 1.31 & 3.0 & 1.43 & $93 \pm 7.81^{a-h}$ & $0.055 \pm 0.011^{b}$ & $1.340 \pm 0.020^{f-k}$ & 60.73 & Effective \\
\hline AUAVR-51 & 2.10 & 3.0 & 1.52 & $87 \pm 6.25^{\mathrm{b}-\mathrm{h}}$ & $0.049 \pm 0.005^{b}$ & $1.490 \pm 0.062^{b-k}$ & 67.58 & Effective \\
\hline AUAVR-52 & 2.10 & 3.5 & 1.65 & $111 \pm 6.56^{\mathrm{ab}}$ & $0.065 \pm 0.007^{b}$ & $1.860 \pm 0.062^{a-c}$ & 84.93 & Highly Effective \\
\hline AUAVR-53 & 1.46 & 3.5 & 1.81 & $87 \pm 8.72^{b-h}$ & $0.086 \pm 0.004^{b}$ & $1.837 \pm 0.045^{\mathrm{a}-\mathrm{d}}$ & 83.56 & Highly Effective \\
\hline+ Ve control & & & & - & - & $2.190 \pm 0.118^{a}$ & 100.0 & Highly Effective \\
\hline -Ve control & & & & - & - & $0.401 \pm 0.106^{1}$ & 18.26 & Less Effective \\
\hline
\end{tabular}

SI(Solubilization Index), CD(Colony Diameter), MGT(Mean Generation Time), NN(Nodule Number),NDW(Nodule Dry Weight), SDW(Shoot Dry Weight), \%SE(Percentage symbiotic Effectiveness)

Key: Levels not followed by the same letter/letters were significantly different at $P<0.05$ (Tukey's b test)

Although the optimum temperature for rhizobia on culture is between $27-39^{\circ} \mathrm{C}$ (Munevar and Wollum, 1981), some of the current isolates such as AUAVR-14, AUAVR 51, AUAVR 52, and AUAVR 53 were tolerant to low temperature to the level of $5^{\circ} \mathrm{C}$. On the other hand, AUAVR 13, AUAVR 47, and AUAVR 53 were tolerant up to $45^{\circ} \mathrm{C}$ (table 3 ). Isolate AUAVR-52 showed growth in wide range of temperature $\left(5-40^{\circ} \mathrm{C}\right)$. Low temperature tolerance of some isolates in laboratory could grant for inoculant production for the highland pulse crop particularly faba bean. Besides, the wide range of temperature tolerance of faba bean rhizobia could assist the isolates to cop up with current global climatic change.
However, there are contradictory reports on the reproducibility of in vitro and in vivo results on stress tolerance. According to Dadarwal et al. (1981) the tolerance of rhizobial isolates to different environmental stresses in in vitro condition has no positive correlation to in vivo nitrogen fixation potential. In contrast, Fitouri et al. (2012) stressed the selection of rhizobial bioinoculant for field application based on stress tolerance level the isolates during in vitro experiment. These contrasting research reports may depend on the type of cultivar, climatic condition of experimental area, and soil type. The two authors also concluded by emphasizing the need of similar trials in other sites using different types of hosts.

Table 3: Stress tolerance and substrate utilization properties of TCP solubilizer Rhizobia

\begin{tabular}{|c|c|c|c|c|c|c|c|c|c|c|c|c|c|c|c|}
\hline \multirow[b]{2}{*}{ Isolates } & \multicolumn{2}{|c|}{$\begin{array}{c}\text { Temperature } \\
\left({ }^{\circ} \mathrm{C}\right)\end{array}$} & \multirow{2}{*}{$\begin{array}{c}\begin{array}{c}\mathrm{NaCl} \\
(\%)\end{array} \\
\\
\sum_{\Sigma}^{\pi} \\
\end{array}$} & \multicolumn{2}{|c|}{$\mathrm{pH}$} & \multicolumn{2}{|c|}{$\begin{array}{c}\text { MaTL }(\mu \mathrm{M}) \\
\text { at pH } 5\end{array}$} & \multicolumn{6}{|c|}{ Maximum IAR Concentration } & \multicolumn{2}{|c|}{$\begin{array}{l}\text { Carboh- } \\
\text { ydrates }\end{array}$} \\
\hline & $\underline{E}$ & $\sum_{\Sigma}^{\vec{\pi}}$ & & $\underline{E}$ & $\sum_{\Sigma}^{\frac{1}{\pi}}$ & 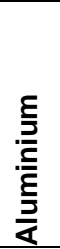 & 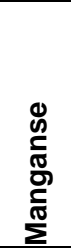 & 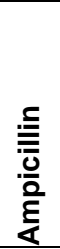 & 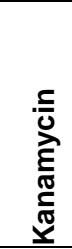 & 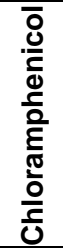 & 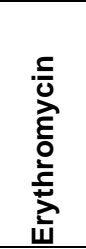 & 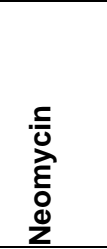 & 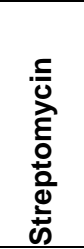 & 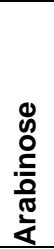 & $\begin{array}{l}\frac{1}{0} \\
\frac{\pi}{\pi} \\
\text { के }\end{array}$ \\
\hline AUAVR-12 & 20 & 40 & 2 & 5 & 10 & 50 & 200 & 5 & 2.5 & 10 & 5 & $<2.5$ & $<2.5$ & - & + \\
\hline AUAVR-13 & 20 & 45 & 0.5 & 5 & 9 & 75 & 200 & 10 & 5 & 10 & $<2.5$ & $<2.5$ & $<2.5$ & + & + \\
\hline AUAVR-14 & 5 & 35 & 5 & 5.5 & 10 & $\mathrm{Nd}$ & $\mathrm{Nd}$ & 2.5 & 2.5 & 5 & $<2.5$ & $<2.5$ & $<2.5$ & + & + \\
\hline AUAVR-29 & 15 & 35 & 4 & 5.5 & 10 & $\mathrm{Nd}$ & $\mathrm{Nd}$ & 2.5 & 2.5 & 10 & 10 & $<2.5$ & $<2.5$ & - & + \\
\hline AUAVR-30 & 10 & 35 & 5 & 6 & 10 & $\mathrm{Nd}$ & $\mathrm{Nd}$ & 5 & 2.5 & 5 & 10 & $<2.5$ & $<2.5$ & - & - \\
\hline AUAVR-34 & 15 & 40 & 3 & 6 & 10 & $\mathrm{Nd}$ & $\mathrm{Nd}$ & 10 & 2.5 & 5 & 10 & $<2.5$ & $<2.5$ & - & - \\
\hline AUAVR-39 & 20 & 30 & 4 & 6 & 10 & $\mathrm{Nd}$ & $\mathrm{Nd}$ & 10 & 2.5 & 5 & 10 & $<2.5$ & $<2.5$ & - & - \\
\hline AUAVR-47 & 15 & 45 & 1 & 5 & 10 & 25 & 200 & 10 & 2.5 & 5 & $<2.5$ & $<2.5$ & 5 & + & - \\
\hline AUAVR-49 & 15 & 30 & 6 & 5 & 10 & 0 & 25 & 10 & 5 & 10 & $<2.5$ & $<2.5$ & 5 & + & - \\
\hline AUAVR-51 & 5 & 30 & 6 & 4.5 & 10 & 75 & 200 & 10 & 5 & 10 & $<2.5$ & $<2.5$ & 5 & + & - \\
\hline AUAVR-52 & 5 & 40 & 6 & 4.5 & 10 & 75 & 200 & 10 & 5 & 10 & $<2.5$ & $<2.5$ & $<2.5$ & + & - \\
\hline AUAVR-53 & 15 & 45 & 1 & 5.5 & 10 & $\mathrm{Nd}$ & $\mathrm{Nd}$ & 10 & 5 & 5 & $<2.5$ & $<2.5$ & 5 & + & - \\
\hline
\end{tabular}

With regard to salt tolerance experiment, three faba bean rhizobial isolates such as AUAVR-49, AUAVR-51 and AUAVR-52, tolerated up to $6 \% \mathrm{NaCl}$ on YEMA (table $3)$. This is in agreement with the research reports that stated the tolerance of fast growing rhizobial isolates to
$\mathrm{NaCl}$ is up to $5 \% \mathrm{NaCl}$ (Zerihun Belay and Fassile Assefa, 2011; Mulisa Jida and Fassil Assefa, 2012). However, there is variation in osmotolerance among rhizobial isolates collected from different hosts (Fitouri et al., 2012). Isolates also showed variation in tolerance to $\mathrm{pH}$ during 


\section{Girmaye Kenasa et al.,}

culturing on Keyser solid growth medium. All isolates grew on media adjusted at $\mathrm{pH}$ of 6-8 which could be considered as the optimum $\mathrm{pH}$ for the growth of the isolates. Although rhizobial isolates showed better tolerance to alkaline $\mathrm{pH}$, only two isolates (AUAVR-51 and AUAVR 52) grew at $\mathrm{pH}$ 4.5 (table 3). Similar results were reported by Zerihun Belay and Fassil Assefa (2011) for vicia faba rhzobia and by Mulissa Jida and Fassil Assefa (2012) for rhizobia isolated from Cicer arietinum L.. According to the current result Rhizobium leguminosarum var viciae were tolerant on the alkaline growth media as compared to acidic growth media. This could be related to the additional extracellular organic acid release by the fast grower isolates which can aggravated their intolerance at low $\mathrm{pH}$ growth media (Sadowsky et al., 1983)

The Intrinsic Antibiotic Resistance (IAR) of the TCPsolubilizer faba bean rhizobial isolates was studied to determine diversity among them. As indicated in table-3 isolates were sensitive to neomycin at all levels of concentration tested. Some isolates were resistant to streptomycine at 2.5 and $5 \mu \mathrm{g} / \mathrm{ml}$. On the other hand, ampicillin and chloromphenicol were indiscriminatory tools to determine diversity among the isolates. AUAVR-49 and AUAVR-51 were the most resistant isolates to antibiotics as compared to the others. Differences in tolerance to different kinds of antibiotics was reported among strains belongs to same species of rhizobia (Amergar et al., 1997). The difference in IAR among Rhizobium leguminsarium isolated from Vicia faba was also emphasized on the research report of Zerihun Belay and Fassil Assefa(2011). Young and Chao (1989) also reported variability in IAR of rhizobium isolated from same host plant at the same time. Thus, IAR test is change tool to study diversity among rhizobium isolated from the same host; in spite of the differences in the action antibiotics.

Isolates were also characterized by growth on basal media containing 12 different carbon sources and eight different nitrogen sources. All isolates showed visible colony on all tested carbon sources, except for arabinose and starch that supported only $58 \%$ and $42 \%$ of the isolates respectively (table-3). Two isolates (AUAVR-13 and AUAVR-14) utilized all the tested carbon sources. All isolates grew on all amino acids tested. The twelve different kinds of carbon sources and the eight nitrogen sources tested in this experiment failed to show diversity among the isolates. According to Amergar et al. (1997) utilization of some specific carbohydrates is the useful traits for differentiating species rhizobia that nodulates beans. However, some of the carbon sources recommended by the author were not included in the current experiment. In the same manner Cepeda and Lucia (2005) also reported that rhizobia that nodulates clover was able to metabolize L-alanine, L- proline and aminobutyric acid, but none of them utilized L-leucine. This indicates that there are some specific substrates that show diversity among phosphate-solubilizer rhizobia. Thus, in order test versatility of the rhizobial isolates with respect to metabolism, diverse kinds of carbohydrates and amino acid should be included.

Tolerance of TCP-solubilizer rhizobia to different concentration of $\mathrm{Al}$ and $\mathrm{Mn}$ was another parameter to study diversity. Five isolates were sensitive to all concentration levels of the toxic metals at $\mathrm{pH} 5$ (table-3). The maximum tolerance level of acidic-Al concentration was $75 \mu \mathrm{M}$ recorded for three isolates (AUAVR-13, 51, and 52). The impact of $\mathrm{Mn}$ on the growth of isolates was
Sci. Technol. Arts Res. J., July-Sep 2014, 3(3): 11-17

insignificant up to the level of $200 \mu \mathrm{M}$ (table 3). This result indicated that as concentration of $\mathrm{Al}$ increases at a specific acidic $\mathrm{pH}$, sensitivity of the isolates increases. According to Keyser et al. (1979) maximum tolerance level of slow growing rhizobia for Al was $50 \mu \mathrm{M}$, and all strains tolerant to $\mathrm{Al}$ were tolerant to $\mathrm{Mn}$ also. The report stressed the toxicity of $\mathrm{Mn}$ to host plant as compared to the little or no influence on the rhizobial strains. The determinant effect of aluminum on rhizobia both in in vitro and in vivo condition was reported by Paudyal et al. (2007). According to Ayanaba et al. (1983) there is correlation between acid-Al sensitivity of isolates with their colony texture, as large-mucoid rhizobial colony were more resistant than dry-pinpoint colonies. Munns and Keyser (1981) observed the better tolerance of fast grower rhizobial isolates to Al toxicity as compared to the slow growers. The current research result also confirmed the former research reports.

The combination of different concentration $\mathrm{Al}$ and $\mathrm{Mn}$ had no unique effect on the growth of the isolates. Specifically, at a fixed concentration of $\mathrm{Al}$, increase in concentration of $\mathrm{Mn}$ had no effect on the growth of isolates up to $200 \mu \mathrm{M}$ (Data not shown). In contrary, the increase in Al concentration on a fixed concentration of $\mathrm{Mn}$ had a significant effect on the survival of the isolates on the culture media. In acid soils, Al toxicity and acidity itself are probably more important limiters of rhizobial growth than $\mathrm{Mn}$ toxicity and $\mathrm{Ca}$ deficiency (Keyser and Munns, 1979). The current research result is in agreement with the former reports. Thus, the response of rhizobial isolates to different levels of acidic-Al was the other parameter to study diversity that could exist among strains of the species.

Symbiotic effectiveness of the rhizobial isolates was measured in terms of NN, NDW, SDW and \%SE. Symbiotic effectiveness of all isolates was categorized under either effective or highly effective. The correlation among TCP-SI, MGT, NN, NDW, SDW, and \%SE was very weak at $P \leq 0.05$ (table 2 ). Three isolates AUAVR-29, AUAVR-52 and AUAVR-53 were symbiotically highly effective similar to the positive control. Especially, the TCP-SI, NN, SDW, and \%SE of isolate AUAVR-52 was the highest. The rhizobial isolate was also tolerant to different in vitro stresses. The lack of significant difference in symbiotic effectiveness (NN, NDW and SDW) among the TCP-solubilizer faba bean rhizobia isolates might be related to the sterile sand culture and the ideal greenhouse environment. According to this particular research there was positive correlation between in vitro stress tolerance and \%SE of TCP solubilizer rhizobia isolate at $P \leq 0.5$. This result was similar to Sharma et al. (2013) who concluded that invitro stress tolerance is an indication for the survival and persistence of rhizobial isolates under severe and harsh desert conditions of real in vivo condition. Keyser et al. (1979) also reported the positive correlation between Al toxicity tolerances and symbiotic effectiveness of some strains. The symbiotic performance of stress tolerant-rhizobial isolates under sterile sand culture in green house may not ensure same conclusion for the real farm land environment. Thus, competitiveness and symbiotic effectiveness of the isolates should be checked under their respective stressed field environment so as to recommend as biofertilizer. In this study, percentage symbiotic effectiveness is good estimator of the symbiotic 
Girmaye Kenasa et al.,

compatibility between host and TCP-solubilizing rhizobial isolate.

\section{CONCLUSIONS}

Acidic soil of Wollega contains Phosphate solubilizing faba bean rhizobia. The TCP solubilizing potential of the isolates varies. The difference in TCP-solubilization depends on some features of the isolates such as growth rate, amount of extracellular organic acid production, metabolic diversity and specialization, and their potential to tolerate different stress environments. TCP-solubilizing rhizobial isolates are fast-grower and organic acid producer. Isolates that have highest TCP-SI were tolerant to stresses such as extreme temperature, concentrated salts, acidic $\mathrm{pH}$, acid-AI, and IAR. Moreover, these isolates also formed effective symbiotic association with the host plant. In this study, tests related to carbon and nitrogen substrate utilization didn't create meaning full result in order to correlate with stress tolerance and symbiotic effectiveness. Thus, the author recommends the succeeding researcher to use wide ranges of carbon and nitrogen sources to test diversity among TCPsolubilizing rhizobial isolates. Moreover, in order to recommend the isolates as biofertilizer repeated field trial should be conducted.

\section{REFERENCES}

Abdenna Deressa., Bikila Bote. and Hirpa Legesse. (2013). Evaluation of Soil Cations in Agricultural Soils of East Wollega Zone in South Western Ethiopia. Science, Technology and Arts Research Journal 2(1): 10-17.

Abere Mnalku, Heluf Gebrekidan and Fassil Assefa (2009). Symbiotic effectiveness and characterization of Rhizobium strain of Faba bean (Viciae faba) collected from Eastern and Western Hararghe highlands of Ethiopai. European Journal of American Studies 11:223244.

Ahmed, M.H., Rafique Uddin, M. and Mclaughlin, W. (1984). Characterization of indigenous rhizobia from wild legumes. FEMS Microbiology Letters 24:197-203.

Alikhani, H.A., Saleh-Rastin, N. and Antoun, H.(2006). Phosphate solubilization activity of rhizobia native to Iranian soils. Plant and Soil 287:35-41.

Amarger, N. Macheret, V. and Laguerre, G. (1999). Rhizobium gallicum sp. nov. and Rhizobium giardinii sp. nov., from Phaseolus vulgaris Nodules. International Journal of systematic Bacteriology 47(4): 996-1006.

Anteneh Argaw (2012). Characterization of Symbiotic Effectiveness of Rhizobia Nodulating Faba bean (Vicia faba L.) Isolated from central Ethiopia. Research Journal of Microbiology 7(6): 280-296.

Ayanaba, A., Asanuma, S. and Munns, D.N. (1983). An Agar Plate Method for Rapid Screening of Rhizobium for Tolerance to Acid-Aluminum Stress. Soil Science Society American Journal 47: 1983.

Beck, D.P., Materon, L.A. and Afandi, F. (1993). Practical Rhizobium-legume technology manual, Technical Manual No: 19. ICARDA, Aleppo, Syria.

Cepeda, H. and Lucia, M. (2005). Phenotypic characterization of rhizobia that nodulate ball clover. Master's thesis, Texas A and M University. Texas $A$ and $M$ University. Available electronically from http://hdl.handle.net /1969.1/2636.
Sci. Technol. Arts Res. J., July-Sep 2014, 3(3): 11-17

Dadarwal, K.R., Kundu, B.S. and Tauro, P. (1981). In vitro and in vivo nitrogenase activity of Rhizobium mutants and their symbiotic effectivity. Journal of Biosciences 3(2): 117-123.

Edi-Premono, M., Moawad, A.M. and Vlek, P.L.G. (1996). Effect of phosphate-solubilization Pseudomonas putida on the growth of maize and its survival in the rhizosphere. Indonesian Journal of Crop Sciences 11:13-23.

Fitouri D.S., Ben, J.F., Zribi, K., Rezgui, S. and Mhamdi, R. (2012). Effect of inoculation with osmotolerant strain of Rhizobium sullae on growth and protein production of sulla (Sulla coronarium L.) under water deficit. Journal of Applied Biosciences 51: 642-3651.

Halder, A.K., Mishra, A.K., Bhattacharyya, P. and Chakrabartty, P.K. (1990). Solubilization of rock phosphate by Rhizobium and Bradyrhizobium. Journal of General and Applied Microbiology 36: 81-92.

Jordan, D.C. (1984). Family III. Rhizobiaceae. In: Bergey's Manual of Systematic Bacteriology, Vol.1, pp. 234-254, (krieg, N.R., Holt, J.G). The Williams and Wilkins, Baltimore.

Keyser, H.H., Munns, D.N. and Hohenberg, J.S. (1979). Acid tolerance of rhizobia in culture and in symbiosis with cowpea. Soil Science Society American Journal 43: 719722 .

Lupwayi, N and Haque, I. (1994). Legume Rhizobium Technology Manual. Environmental Sciences Division International Livestock Center for Africa. Addis Ababa, Ethiopia. Pp.1-93.

Maatallah, J., Berroho, E.B., Sanjuan, J. and Lluch, C. (2002). Phenotypic characterization of rhizobia isolated from chickpea (Cicer arietinum) growing in Moroccan soil. Agronomie 22: 321-329.

Mazur, A., Stasiak, G. Wielbo, J. Koper, P. Kubik-Komar, A. and Skorupska, A. (2013). Phenotype profiling of Rhizobium leguminosarum bv. trifolii clover nodule isolates reveal their both versatile and specialized metabolic capabilities. Archive of Microbiology 195: 255267.

Mulissa Jida and Fassil Assefa (2011). Phenotypic and plant growth promoting characteristics of Rhizobium leguminosarum bv. viciae from lentil growing areas of Ethiopia. African Journal of Microbiology Research 5(24): 4133-4142.

Munevar, F. and Wollum, A. (1981). Growth of Rhizobium japonicum Strains at Temperatures Above $27^{\circ} \mathrm{C}$. Applied and Environmental Microbiology 42(2): 272-276.

Munns, D.N. and Keyser, H.H. (1979). Effects of calcium, manganese and aluminum on growth of rhizobia in acid media. Soil Science Society American Journal 43: 500503.

Munns, D. N. and Keyser, H. H. (1979). Tolerance of rhizobia to acidity, aluminum, and phosphate. Soil Science Society American Journal 43: 519-523.

Munns, D.N. and Keyser, H.H. (1981). Response of Rhizobium strains to acid and Aluminium stress. Soil Biology \& Biochemistry 13:115-118.

Munns, D.N. (1978). Soil acidity and Nodulation. In: Mineral nutrition of legumes in Tropical and subtropical Soil, pp.247-263 (Andrew C.S. and Kamprath E.J., eds.). Common wealth Scientfic and Industrial Research Organisation. 


\section{Girmaye Kenasa et al.,}

Paudyal, S.P., Aryal, R.R., Chauhan, S.V.S. and Maheshwari, D.K. (2007). Effect of Heavy Metals on Growth of Rhizobium strains and Symbiotic Efficiency of two species of tropical legumes. Scientific World 5(5): 2732.

Peix, A., Rivas, R., Mateos, P.F., Molina-Martínez, E., Barrueco- Rodriguez, C. and Velázquez, E. (2001). Growth promotion of chickpea and barley by a phosphate solubilizing strain of Mesorhizobium mediterraneum under growth chamber conditions. Soil Biology and Biochemistry 33: 103-110.

Rice, W.A., Penney, D.G. and Nyborg, M. (1977). Effect of siol acidity on rhizobial numbers, nodulation and nitrogen fixation by alfalfa and red clover. Canadian Journal of Soil Sciences 57:197-203.

Sadowsky, M.J., Keyser, H.H. and Bohlool, B.B. (1983). Biochemical characterization of fast- and slow-growing rhizobia that nodulate soybeans. International Journal of Systematic Bacteriology 33(4): 716-722.

Sharma S.R., Rao, N.K., Gokhale, T.S. and Ismail, S. (2013). Isolation and characterization of salt-tolerant rhizobia native to the desert soils of United Arab Emirates. Emirates Journal of Food and Agriculture 25(2): 102-108.

Somasegaran, P. and Hoben, H.J. (1994). Handbook for Rhizobia. Springer-Verlag, pp.380.
Sci. Technol. Arts Res. J., July-Sep 2014, 3(3): 11-17

Song, O.R., Lee, S.J., Lee, Y.S., Lee, S.C. Kim, K.K. and Choi, Y.L. (2008). Solubilization of Insoluble Inorganic Phosphate by Burkholderia Cepacia Da23 Isolated from Cultivated Soil. Brazilian Journal of Microbiology 39: 151156.

Vincent, J.M. (1970). A Manual for the Practical Study of Root-Nodule Bacteria. IBP Handbook 15. Blackwell Scientific Publications, Oxford, pp.164.

White, D. (1995). The physiology and biochemistry of prokaryotes. Oxford University Press, Oxford, pp. 378.

Young, C.C. and Chao, C.C. (1989): Intrinsic antibiotic resistance and competition in fast- and slow- growing soybean rhizobia on a hybrid of Asian and US cultivars. Biology and Fertility of Soils 8(1): 66-70.

Zahran, H.H. (1999). Rhizobium-Legume Symbiosis and Nitrogen Fixation under Severe Conditions and in an Arid Climate. Microbiology and Molecular Biology Reviews 63(4): 968-989.

Zerihun Belay and Fassil Assefa (2011). Symbiotic and phenotypic diversity of Rhizobium leguminosarum bv. viciae from Northern Gondar, Ethiopia. African Journal of Biotechnology 10(21): 4372-4379. 